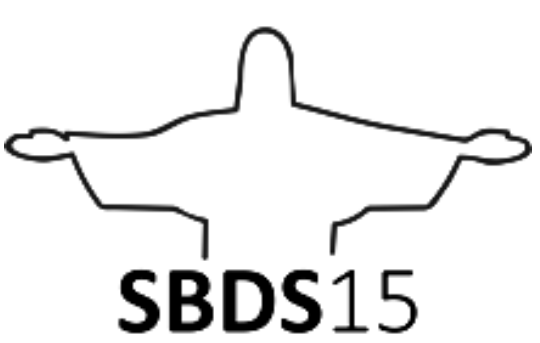

5 SIMPÓSIO DE DESIGN SUSTENTAVEL

Rio de Janeiro, 11 de novembro a 13 de novembro de 2015

\title{
DESIGN SUSTENTÁVEL RADICAL: A “FORMA SEGUE O SIGNIFICADO" EM STUART WALKER
}

\author{
Lucas Farinelli Pantaleão \\ FAAC/UNESP \\ lucasfarinelli@gmail.com \\ Olympio José Pinheiro \\ FAAC/UNESP \\ holihn@uol.com.br
}

\begin{abstract}
Resumo: Delineia-se uma introdução panorâmica, de abordagem radical, acerca do design de produtos sustentáveis na conceptualização de Stuart Walker. Procura-se evidenciar o mote denominado pelo autor, "a forma segue o significado", através de seu "design proposicional" norteado pela lógica "projetar sustentabilidade": uma prática de pesquisa acadêmica em design sustentável que fundamenta-se em seu próprio processo criativo, cuja metodologia visa o desenvolvimento de objetos funcionais imbuídos de significado humano a partir da relação entre o material e o espiritual. Objetiva-se contribuir para a reflexão de projeto e planejamento de produtos, nos quais se articulem uma nova concepção do design, onde o foco destina-se a promover alternativas de subverter a atual cultura material, no contexto da sociedade pós-industrial contemporânea.
\end{abstract}

Palavras-chave: Design de Produto, Design Sustentável Radical, Design Proposicional, "A Forma Segue o Significado", Stuart Walker.

\begin{abstract}
Outlines a panoramic introduction of radical approach, about sustainable products design in the conceptualization of Stuart Walker. Wanted highlight the theme named by the author, "form follows meaning," through his "propositional design" guided by the logic "designing sustainability": a practical academic research in sustainable design based on their own creative process, whose methodology aims to develop functional objects imbued with human meaning from the relationship between the material and the spiritual. The objective is contribute to reflection of design and product planning, to articulate a new conception of design, where the focus is intended to promote alternatives to subvert the current material culture in the context of contemporary post-industrial society.
\end{abstract}

Keywords: Product Design, Sustainable Radical Design; Propositional Design, "Form Follows Meaning", Stuart Walker. 


\section{INTRODUÇÃO}

Após mais de um século de design voltado à produção em massa, a evolução da tecnologia, responsável pela flexibilização dos processos de fabricação de uma infinidade de bens, num processo quase frenético de mutação constante, apresentanos poucas evidências de que os desdobramentos do design, produção e consumo sejam capazes de nos fazer mais felizes. Em contrapartida, fica cada vez mais explícito como são responsáveis por contribuir para uma devastação ambiental sem precedentes ampliando o abismo da desigualdade e da exploração social.

Em qualquer discussão sobre design sustentável, reconhecessem-se as consequências nefastas de nossas atividades atuais de produção e consumo, mas é imprescindível ir além. Não basta simplesmente permear a superficialidade da concepção de (novos/mais) produtos ecologicamente corretos. É preciso desafiar, em profundidade, nossos (pré)conceitos de como nos relacionamos com os produtos, objetos e/ou artefatos. Possivelmente este seja um caminho para reformularmos nossas atuais concepções e reavaliarmos nossas noções de estética e experiência de projeto e planejamento do produto.

Não obstante as últimas décadas terem sido marcadas, paralelamente, por um interesse crescente em ações de combate à cultura do consumo e em prol da sustentabilidade, a realidade é que, segundo Stuart Walker, ainda se tem dado relativamente "pouca atenção às competências criativas essenciais e às potenciais contribuições do designer" (WALKER, 2005, p. 47). Apesar de podermos verificar o emprego de tecnologias muito sofisticadas por parte das indústrias modernas, o autor afirma que,

\footnotetext{
a abordagem fundamental do design, produção e distribuição de produtos tem permanecido essencialmente a mesma por pouco mais de um século [...] Mais frequentemente ainda, o foco gravita entre questões periféricas como a análise do ciclo de vida ou uso de materiais reciclados. [...] Este sistema, o qual tem se tornado crescentemente automatizado ao longo dos anos, é principalmente unidirecional em termos do seu fluxo de recursos e energia (Idem op. cit., p. 47-8).
}

Walker, cuja obra compõe o referencial teórico fundamental deste nosso trabalho, é professor e pesquisador de projeto sustentável no laboratório de pesquisa Imagination Lancaster pela University of Lancaster, Reino Unido. Passou grande parte de sua carreira acadêmica no oeste do Canadá, onde foi decano associado da Faculdade de Design Ambiental na Universidade de Calgary. Sua pesquisa tem como foco a estética do design de produtos sustentáveis e seus trabalhos concentram-se na "estética sustentável"1 do produto e sua re-significação. Desenvolve um "design proposicional" 2 que tem sido exibido em apresentações exclusivas no Design Museum em Londres, Canadá e Europa (Figura 1 - Stuart Walker).

\footnotetext{
1 "Sustainable Aesthetics" vide WALKER, S. 2006, p. 186.

2 "Propositional Designs" vide WALKER, S. 2013, p. 462-4.
} 


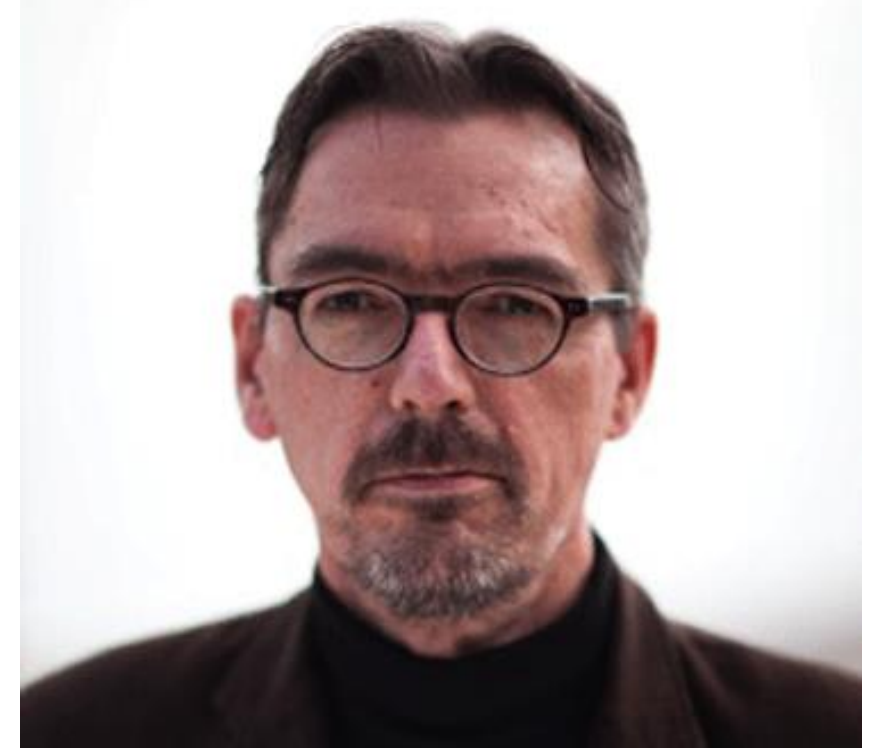

Figura 1 - Stuart Walker. Fonte: http://stuartwalker.org.uk/

A pesquisa de Walker explora uma variedade de temas relacionados como "Design for Sustainability" e "Design and Meaning and Aesthetics", nos quais emprega o próprio processo criativo do design como metodologia de investigação, priorizando tanto a prática experimental, quanto o potencial criativo sustentável do ato de projetar.

Na tentativa de promover uma contribuição, em âmbito nacional, no tocante à questões de projeto e planejamento dos produtos, objetiva-se proporcionar ao design, uma atualização do presente contexto no que se refere à noções de "Design Sustentável Radical", fundamentadas a partir de Stuart Walker. Trata-se de introdução panorâmica ao pensamento do autor no que tange à aspectos relativos à pesquisa em design para sustentabilidade e a importância da prática projetual como um possível caminho para transpor a atual lógica instrumental de eficiência da produção.

Procura-se evidenciar o mote denominado pelo autor, "a forma segue o significado", através de seu "design proposicional" norteado por sua lógica particular de "projetar sustentabilidade": uma metodologia criativa que visa levar o design para além das características muitas vezes superficiais e prejudiciais, responsáveis por estabelecer o sucesso do consumismo.

Com esta referência procuramos contribuir para a criação e reflexão de projetos de produto, nos quais se articulem uma nova concepção do design, cuja metodologia de pesquisa procura alternativas de subverter a atual cultura material a fim de sintonizar com os novos paradigmas sistêmicos, holísticos e ecológicos, no contexto da sociedade pós-industrial contemporânea.

\section{DESENVOLVIMENTO: design de produto sustentável e sustentabilidade}

Stuart Walker, ao evidenciar a natureza insustentável de muitas das práticas atuais, procura criar uma oportunidade para idealizar uma abordagem mais construtiva e mais profunda, que acredita ser, por natureza, mais sustentável (WALKER, 2006, p. 2-3). Ao recordar que é imperativo reconhecer a importância de que muitos desenvolvimentos da ciência e da tecnologia foram, e ainda são, responsáveis por proporcionarem genuínas e valiosas contribuições para nossa espécie, questiona: 
If [...] the creation of new products is, indeed, part of the problem rather than the solution, then what is left for the designer? Does the designer still have a contribution to make? ${ }^{3}$ (WALKER, 2008, p. 6).

O autor argumenta que dentro dos parâmetros convencionais do design de produto, tudo nos leva a crer que a resposta a essas questões seria não, ou no máximo, relativamente pouco. No entanto, acredita que se estivermos preparados para ampliar nossos horizontes e passarmos a ver os designers além de criadores de novos produtos, mas criativos que pensam e contribuem para a natureza, concepção e significado da cultura material, então eles deverão desempenhar um papel importante na re-conceptualização e redefinição de nossas noções de objetos funcionais (Idem ibidem).

Ressalta ainda que uma alternativa importante seria separar o design, ao menos temporariamente, de questões de ordem econômica, na tentativa de libertá-lo das pressões do ambiente dos negócios, a fim de facilitar uma contribuição mais reflexiva e, talvez, consequentemente mais significativa: "if designers are to address the challenge of sustainability in a more substantive manner, they must question the ways in which they design, the assumptions they make, and the products of design" 4 (Idem op. cit., p. 6).

Walker reconhece que "sustainable design is a vast subject that we have barely begun to tackle and so it would be unwise to attempt a definitive solution to what is, in reality, an embryonic, dynamic and volatile area of human endeavor" (WALKER, 2014, p. 2-3).

Contrariando as definições mais finas $^{6}$ de distinção entre os conceitos de "sustentabilidade" e "desenvolvimento sustentável", Walker propõe uma interpretação mais abrangente e integrativa destes termos, com o objetivo de tornalos mais tangíveis e, consequentemente, mais viáveis e com maior potencial para a realização efetiva.

Utiliza o termo "desenvolvimento sustentável" de forma a descrever um amplo processo de desenvolvimento em que as preocupações de ordem econômicas, ambientais e sociais são consideradas de maneira simultânea, ao passo que se refere ao termo "sustentabilidade" para designar os modos de vida cujas preocupações são abraçadas pela responsabilidade e permeiam vários esforços neste sentido.

Ciente das ambiguidades e divergências que as definições mais finas podem proporcionar, julga razoável sua forma de abordar tais conceitos, uma vez que admite que alcançar um desenvolvimento que seja verdadeiramente sustentável ou, a sustentabilidade, de fato, pode muito bem ser impossível (WALKER, 2006, p. 5-6).

Em suas palavras:

\footnotetext{
3 "Se [...] a criação de novos produtos é, na verdade, parte do problema ao invés da solução, então o que resta para o designer? Será que o designer ainda tem alguma contribuição a fazer?" (Tradução nossa).

4 "Se os designers pretendem enfrentar o desafio da sustentabilidade de uma maneira mais substancial, eles devem questionar as formas como projetam, os pressupostos que partem, e o próprio design de produto" (Tradução nossa).

5 "design sustentável é um assunto amplo que mal começamos a enfrentar, e por isso certamente seria insensato procurar uma solução definitiva para o que é, na realidade, uma área embrionária, dinâmica e volátil do esforço humano" (Tradução nossa).

${ }^{6}$ PEARCE, D.; MARKANDYA, A. \& BARBIER, E. B. 1989; RODRIGUES, V. J. 2009.
} 
While there may be merit in this view, I see both terms as being useful to describe our current attempts to come to terms with the economic, environmental and social concerns that we are facing in contemporary society. In the fields of product design and production, these three priorities are inextricably interwoven and inseparable and it does not seem to me very helpful to draw potentially divisive distinctions ${ }^{7}$ (Idem op. cit, p. 5).

Walker faz questão de afirmar que, para ele, as distinções mais sutis no que compete às noções de sustentabilidade no design não se encontram nos campos da terminologia, mas, sim, no âmbito da fundamentação.

Para o autor, o que importa é concentrar as atividades do design a fim de projetar de forma diferente, trabalhando de modo social, ambiental e economicamente responsável. Neste sentido, ao reconhecer igualmente a utilidade de ambos os termos, esclarece sobre a importância de uma imersão mais profunda e significativa no processo criativo do design:

... it is about fully engaging in the world in a way that is empathetic, intuitive and aesthetic. If we are to immerse ourselves in the creative design process and become aware, through this immersion, of the beauty and fragility of the world, then the fruits of our endeavors will reflect this. It is not so much a matter of rational proof but a matter of faith and hope; faith that goodness can prevail and hope for a better future for all ${ }^{8}$ (Idem, op. cit, p. 6).

Neste sentido, vejamos a tabela de ressignificação do design (Figura 2 Resignificando o design), proposta por Walker, em que compara as característicaschave do design convencional frente ao que o autor considera fundamental em um design que se diga, sustentável:

\begin{tabular}{l|l}
\hline Conventional design & Sustainable design \\
\hline Industrial design & $\begin{array}{l}\text { Design of functional } \\
\text { objects }\end{array}$ \\
\hline Product design & $\begin{array}{l}\text { Creation of material } \\
\text { culture }\end{array}$ \\
\hline Specialization & Improvisation \\
\hline Conventional & Uncertain, uncomfortable \\
\hline Professional & Amateur, dilettante \\
\hline Specific & Holistic, integrative \\
\hline Instrumental & Intrinsic \\
\hline Problem-solving & Experimenting \\
\hline Solutions & Possibilities \\
\hline A priori design & Contingent design \\
\hline
\end{tabular}

Figura 2 - Resignificando o design: uma comparação entre características-chave.

Fonte: WALKER, 2006, p. 38

\footnotetext{
7 “Embora possa haver mérito nestes pontos de vista, vejo os dois termos como sendo úteis para descrever nossas atuais tentativas de se estabelecer um consenso frente as preocupações econômicas, ambientais e sociais que enfrentamos na sociedade contemporânea. Nos campos do design de produto e produção, estas três prioridades estão intrinsecamente entrelaçadas e são inseparáveis, o que não me parece muito útil a não ser para estabelecer distinções e gerar polêmicas (Tradução nossa).

8 “... trata-se de se envolver totalmente no mundo de uma forma que seja empática, intuitiva e estética. Se queremos imergir no processo criativo de design e torná-lo consciente, é através desta imersão, na beleza e fragilidade do mundo, que os frutos de nossos esforços irão, então, se refletir. Não é tanto uma questão de comprovação racional, mas uma questão de fé e esperança; fé de que a bondade pode prevalecer e esperança em um futuro melhor para todos" (Tradução nossa).
} 


\subsection{Stuart Walker: "Projetando Sustentabilidade" e "Design Proposicional"}

Segundo Cardoso, "à medida que a produção industrial vai se tornando mais precisa e diferenciada, é no âmbito eminentemente subjetivo da experiência e da emoção que as verdadeiras decisões de projeto deverão se dar" (CARDOSO, 2008, p. 236).

Para o pensamento original florescer, Walker insiste que não basta focalizar na competência técnica e/ou proficiência do design, é preciso valorizar e cultivar o desconhecido, o atípico e até mesmo o desconcertante. Agindo deste modo, ideias verdadeiramente criativas de valores perduráveis serão raras e de difícil conquista, mas fatalmente irão surgir a fim de suprir a urgência atual no âmbito de projeto e produção (WALKER, 2006, p. 9).

Frente à necessidade imperativa do design de produto prestar sua contribuição para uma (auto)conscientização da produção dos objetos funcionais, é imprescindível que se reflita sobre os efeitos indesejáveis inerentes à sua própria natureza.

Para promover alternativas verdadeiramente sustentáveis, principalmente no tocante à sensibilidades e valores da atual cultura material, é preciso caminhar em direção à um design cujas responsabilidades econômicas, ambientais e sociais, partilhem de valores mais significativos e duradouros. Antes que os excessos de nossas preocupações consumistas acabem por enterrar-nos vivos no lixo, na poluição e na pura banalidade.

De acordo com Walker, o ato de concentrar-se sobre os significados e valores da cultura material é capaz de proporcionar ao design industrial um significativo evoluir que, naturalmente e, inevitavelmente, contribua para a evolução de sua definição estética, libertando-o das restrições de projeto provenientes da definição estritamente comercial dos produtos.

Através da prática acadêmica de um design fundamentado no seu próprio processo criativo, o foco principal da obra de Walker visa o desenvolvimento de objetos funcionais com valores substanciais imbuídos de significado humano. Dentre sua peculiar abordagem, toma como premissa a relação entre o material e o espiritual, bem como a perenidade de artefatos culturais historicamente singulares em ambas as tradições, ocidentais e orientais, a fim de nortear o processo criativo do ato de "projetar sustentabilidade" (designing sustainability).

Por meio de um processo criativo cíclico, de desenvolvimento de artefatos definidos, que vai da reflexão teórica à concepção/contemplação introspectiva, constantemente intermediado pela autoavaliação crítica em que o designer verifica a aplicação de ideias gerais (abstratas) do processo, Walker acredita no papel fundamental do conhecimento tácito como forma de materializar o pensamento sustentável.

Muitas vezes isento de preocupações de ordem econômica, basicamente procura desenvolver explorações experimentais-especulativas, mediadas pela reflexão e autocrítica da argumentação racional (WALKER, 2011, p. 3).

A concepção/contemplação, encaminha as soluções estéticas através de um "design de objetos proposicionais", ou de um "design proposicional" (propositional design), como prefere denominar o resultado de sua abordagem (WALKER, 2006, p. 12; 2011, p. 3-4; 2014, p. 1).

Vejamos como o autor expressa o "design proposicional" de uma forma holística não textual: 
The results of such work are not design solutions but design propositions that ask us to consider if this or that synthesis is a useful contribution to our developing understandings of where design could and, more importantly, should be heading. Such propositions can enable us to see things in new ways, to question our assumptions, to grasp new possibilities and directions. They constitute a holistic, nontextual form of expression that encompasses and conveys ideas, arguments, and possibilities. Hence, this kind of noncommercial, academic, research-based designing, together with outcomes, can be termed propositional design ${ }^{9}$ (WALKER, 2013, p. 449).

Após traçar um diagnóstico de nossas atuais concepções de tempo e relevância do design sustentável frente às características mercadológicas da atual cultura material, Walker focaliza seus esforços em soluções criativas de projeto, ao invés de se focalizar na análise de problemas ambientais de produção e consumo.

Acredita que o design pode ser visto como um ingrediente essencial para uma abordagem de pesquisa mais holística. Deste modo combinaria "rational analysis, cognitive knowledge, and explanation with intuitive decision-making, tacit knowledge, and expression", bem como "theory and general principles with discrete, case-specific syntheses ${ }^{10 "}$ (Idem, op. cit, 451).

Vejamos o esquema (Figura 3 - Pesquisa em design fundamental baseado na prática) proposto por Walker em que ilustra os três pilares de sua abordagem, cujo processo criativo se apoia na prática de design denominada "thinking-and-doing" (pensar-e-fazer):

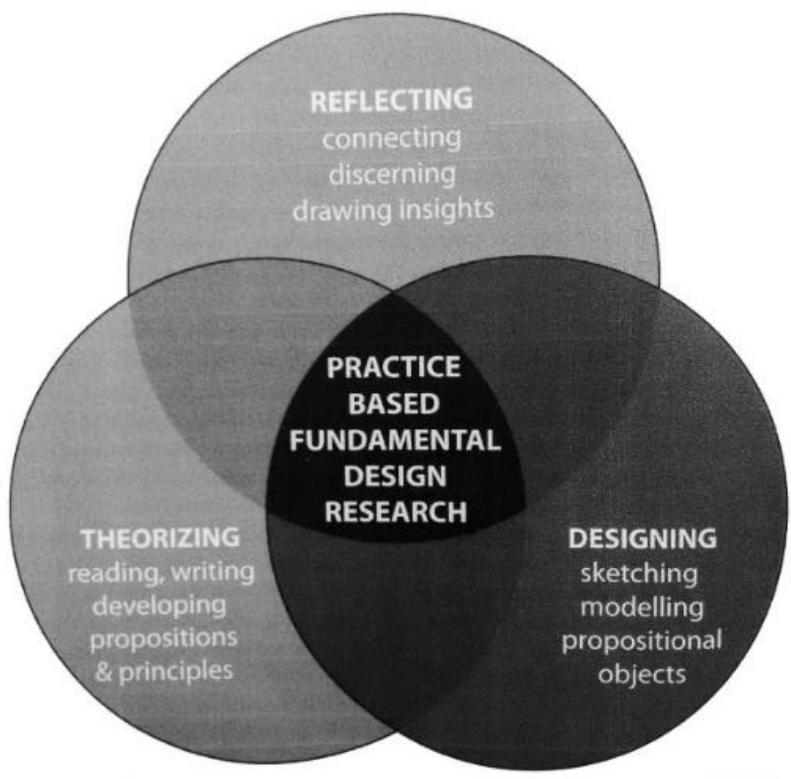

Figura 3 - Pesquisa em design fundamental baseado na prática. Fonte: WALKER, 2013, p. 450

\footnotetext{
9 "Os resultados de tal trabalho não se constituem em projetar soluções, mas proposições de design que nos levam a considerar se esta ou aquela síntese pode prestar uma contribuição útil para nossos entendimentos de desenvolvimento de onde o design poderia e, mais importante, deveria ser direcionado. Tais proposições podem permitir-nos ver as coisas de novas formas, a questionar nossas suposições a fim de captar novas possibilidades e direções. Constituem uma forma holística de expressão não-textual que engloba e transmite ideias, argumentos e possibilidades. Desta forma, caracteriza um tipo não-comercial, acadêmico, de concepção baseada na investigação, juntamente com os resultados, que pode ser denominado design proposicional" (Tradução nossa).

10 "análise racional, conhecimento cognitivo e interpretação, com tomada de decisão intuitiva, conhecimento tácito, e expressão, bem como teoria e princípios gerais distintos na síntese específica para cada caso" (Tradução nossa).
} 
Explicação verbal do esquema:

- "Theorizing" (Teorizando): desenvolvimento oral através de discussão de posições teóricas e análise fundamentada, articulando as potenciais implicações desses argumentos frente a cultura material, bem como o desenvolvimento de intenções e critérios para o comprometimento do design. Este aspecto do processo de investigação requer contextualização e muita leitura, escrita e pensamento, todas as etapas são realizadas juntamente com a concepção e reflexão sobre os resultados emergentes.

- "Designning" (Projetando): transmutação das implicações teóricas e critérios em proposições de design que englobam e expressam ideias, e que questionam se essas manifestações oferecem contribuições distintas ou indicações convincentes e construtivas para seguir em frente. Esta fase utiliza o design e habilidades de visualização envolvendo materiais, esboços, o ato de fazer e de manifestar.

- "Reflecting" (Refletindo): permeia todo o processo, a contemplação das ideias teóricas e critérios e a reflexão sobre os resultados proposicionais conectam-se para sintetizar o esforço e agir como um trampolim para as fases subsequentes da pesquisa. Refletindo sobre as leituras, escritas, e proposições de projeto, envolvem períodos de contemplação, onde aparentemente nada está sendo feito. No entanto, valorizando e contemporizando a reflexão podem render, espontaneamente, uma consciência intuitiva e súbitos insights, em que descontinuidades e discordâncias tornam-se unificadas e harmonias são encontradas. A reflexão é fundamental para o processo, e assim como a atividade de projeto, é também uma atividade baseada na prática, que se beneficia pela disciplina, persistência e experiência (Idem op. cit, p. 450-1). (Tradução nossa).

\subsection{Pesquisa acadêmica fundamental em design: teoria e prática proposicional}

Por sua conjectura não implicar necessariamente noções de experimentação científica cartesiana, sistemática, ou investigações de ordem objetiva e análise quantitativo-qualitativa, Walker declara que relutou em utilizar em seu trabalho o termo "pesquisa". Defende que estudos de criatividade em design nem sempre seguem caminhos lineares, muitas vezes, nem sequer caminhos lógicos.

Por este motivo explica que prefere adotar uma análise mais próxima da compreensão fenomenológica, no sentido de abrir caminho para a consideração pessoal, a reflexão introspectiva e as experiências vividas. Em síntese, trata-se de facilitar a consciência direta através do próprio processo de design através da tomada de decisões intuitivas.

Por conta do elevado grau de abstração e subjetividade presente na prática do design, Walker considera praticamente impossível mensurar com precisão os resultados de um projeto/objeto por meio de verificadores independentes ou metodologias unificadoras: "Indeed, for a given problem, if different designers were all to arrive at the same result we would be sorely disappointed. In design we seek and expect variety not consistency ${ }^{11 "}$ (WALKER, 2006, p. 4).

Neste sentido, ao expor aquilo que considera como uma pequena, mas significativa distinção entre o que pode ser interpretado como "design research" (pesquisa em design), reforça a importância de obter um feedback avaliativo para seu design proposicional frente ao design aplicado e ao procedimento utilizado.

\footnotetext{
11 "Na verdade, para um determinado problema, se diferentes designers chegarem todos ao mesmo resultado, ficaríamos muito desapontados. Em design buscamos e esperamos variedade não consistência" (Tradução nossa).
} 
Para Walker, "pesquisa em design", ao contrário de como pode ser entendido no meio acadêmico ("scholarly research"), refere-se ao processo de design que inclui a prática como um modo de exploração, expressão e aprendizado (WALKER, 2013, p. 447). O que talvez poderíamos traduzir como a distinção entre "pesquisa aplicada em design" e "pesquisa fundamental em design".

Procura deixar claro àquilo que considera como diferencial em sua abordagem e como procede para obter uma validação desta abordagem não convencional:

In commercially oriented or applied design research, object concepts and product proposals are commonly used to gauge people's responses - through focus groups, surveys, or observational studies. This kind of qualitative data acquisition is not necessarily appropriate for propositional objects that explore and express theoretical ideas within an academic research agenda; this is a form of fundamental or pure design research rather than applied. [...] Instead, such conclusions are disseminated via conference presentations, journal papers, and books, and the validity and value of the conclusions are assessed by an informed audience of peers. Propositional objects, as an element of fundamental design research, can be treated in the same way ${ }^{12}$ (WALKER, 2013, p. 452).

O esquema abaixo (Figura 4 - Processo do Design Proposicional) ilustra as etapas do processo de "design proposicional" de Walker:

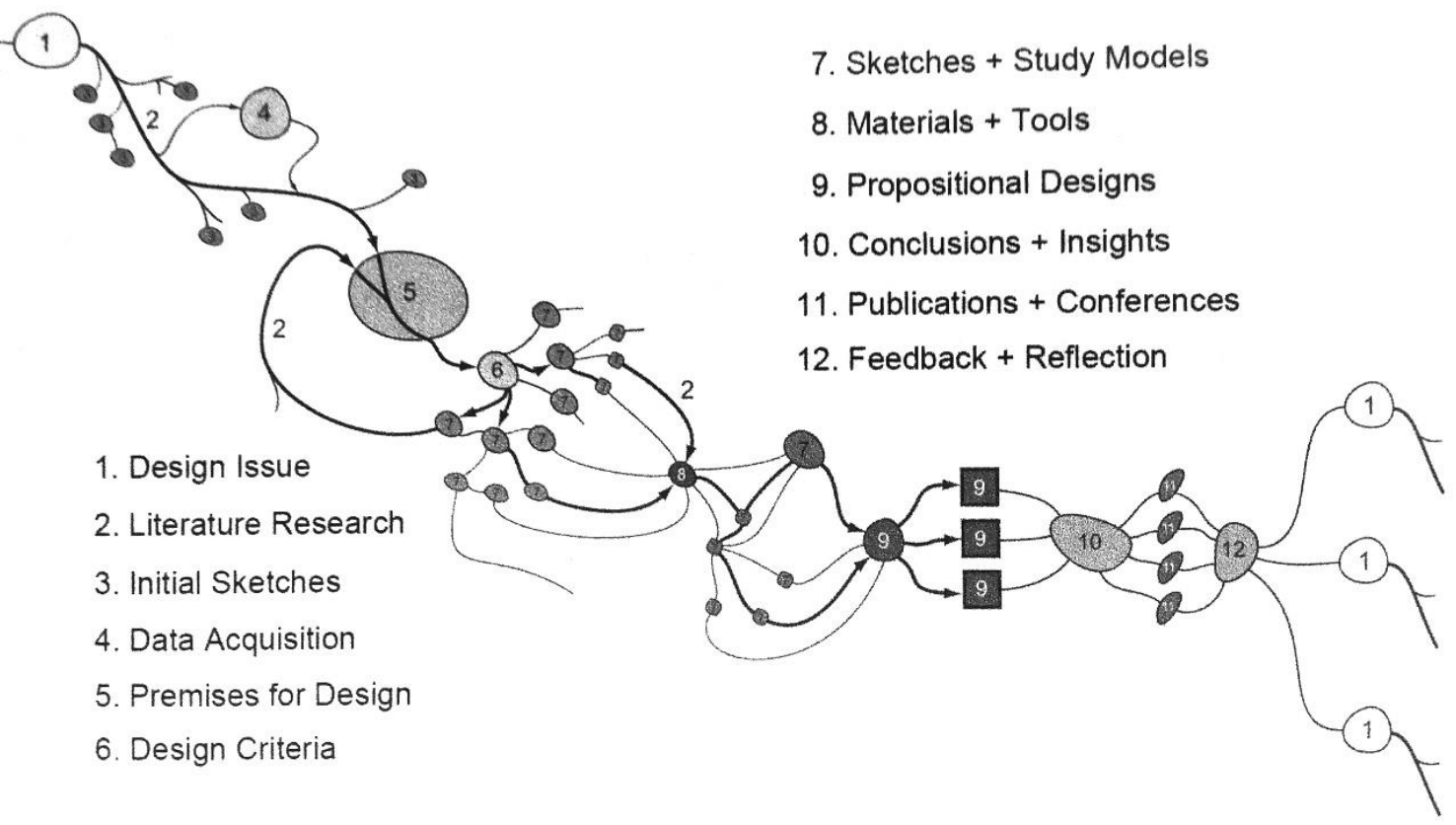

Figura 4 - Processo do Design Proposicional. Fonte: WALKER, 2013, p. 454

\footnotetext{
12 "Na pesquisa em design aplicada ou comercialmente orientada, conceitos de objetos e propostas de produtos são comumente utilizados para medir respostas populares - por meio de público alvo, questionários avaliativos ou estudos de caso. Este tipo de aquisição de dados qualitativos não é necessariamente apropriado para objetos proposicionais que exploram e expressam ideias teóricas dentro de uma agenda de pesquisa acadêmica; esta é uma forma de pesquisa fundamental e pura em design, ao invés de aplicada. [...] Como alternativa, os resultados são divulgados através de conferências, apresentações de artigos em revistas e livros, e posteriormente a validade e o valor das conclusões são avaliadas por um público especializado. Objetos proposicionais, como um elemento de investigação fundamental do design, tem o direito de ser tratado do mesmo modo" (Tradução nossa).
} 
Para Walker, o design situa-se no ponto de encontro entre a ciência e a arte: "... but it is neither science nor art, it is simply and fascinatingly design ${ }^{13 \prime \prime}$ (Idem op. cit, $p$. 5). Os resultados de suas abordagens, muitas vezes normativos e contingentes, podem ser considerados polêmicos, principalmente devido ao foco particular no design sustentável.

No entanto, justifica que o design incide sobre ambos os modos objetivos e subjetivos do pensar e interagir com o mundo. Neste sentido, seu design proposicional sugere uma direção para longe da inovação inconsequente e do utilitarismo de objetos que são prontamente descartados. Trata-se de um esforço para o desenvolvimento de uma cultura material mais significativa e duradoura, cuja ênfase no simbólico visa a produção de objetos com valores mais perenes: "It is my hope that this direction will bring us a little closer to a more sustainable vision for design ${ }^{14 "}$ (Idem, op. cit., p. 6).

Os objetos proposicionais apresentados por Walker incorporam explorações conceituais de temporalidade, produção local, reuso de artefatos industriais descartados e de tecnologias ultrapassadas ou fora de moda, (re)interpretação e (re)valorização da estética. Além da forte ênfase na utilização de materiais naturais em estado "bruto", como pedras, folhas, troncos e galhos de árvores ou alimentos a fim de representar a natureza efêmera e perecível da matéria (Figura 5 - Exemplos Objetos Proposicionais Walker).

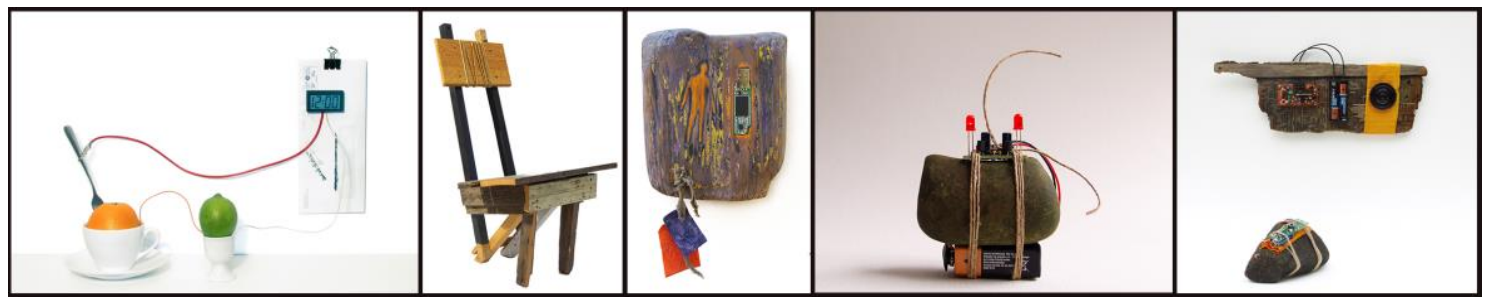

Figura 5 - Exemplos Objetos Proposicionais Walker. Fonte: http://stuartwalker.org.uk/

Constituem-se basicamente de objetos híbridos que combinam tecnologias com formas arquetípicas, a fim de evidenciar a funcionalidade prosaica e aludir para noções de significado humano mais profundo, a partir de um entendimento mais holístico e perene, como consequência de vista espiritual/essencial (WALKER, 2011, p. $3)$.

Walker acredita que essas explorações são capazes de criar uma base sólida para uma nova abordagem do design de produto, pois desafiam muitos paradoxos de longa data suspeitos no design. Como por exemplo, o princípio modernista, para ele, precoce, "a forma segue a função", ou o contraponto pós-moderno que prioriza as experimentações extravagantes ou as variações da moda cuja justificação reside na mera exploração inconsequente da modificação experimental ao bel prazer.

Ao resumir seu trabalho com o mote "form follows meaning" (a forma segue o significado), acredita que este seja o caminho para transpor a lógica instrumental de eficiência da produção. Busca levar o design para além das características muitas vezes superficiais e prejudiciais, desenvolvidas ao longo das décadas passadas, que

\footnotetext{
13 “...mas não é nem ciência, nem arte, é simplesmente e fascinante, design” (Tradução nossa).

14 “Minha esperança é que essa direção vai nos trazer um pouco mais para perto de uma visão mais sustentável para o design" (Tradução nossa).
} 
foram responsáveis por estabelecer o sucesso do consumismo, mas que estavam pouco preocupadas com suas próprias consequências (Idem, op. cit., p. 4).

Assim descreve este aspecto particular de seu trabalho:

Form follows meaning - In this way, localized craft is combined with globalized mass-production, natural materials and traditional forms with digital Technologies, and short-lived functionality with enduring meaning. Form becomes delinked from function. [...] Their purpose is as much about aesthetic experience and reflection as about the requisites of functional necessity. The result is a new kind of hybrid object that merges old and new, reason and intuition, global and local, and where form follows meaning ${ }^{15}$ (Idem, op. cit, p. 192-205).

\section{CONSIDERAÇÕES FINAIS}

Ao visionar um design sustentável que tenta subverter o paradigma mundanomaterialista, paulatinamente instituído ao longo da evolução humana, embora com mais força após a Revolução Industrial, globalização e aceleração da cultura de consumo, verifica-se que a noção radical de design de produto sustentável em Stuart Walker baseia-se fundamentalmente em uma compreensão mais profunda (espiritual/essencial) da sustentabilidade, intimamente associada ao processo criativo baseado na prática projetual do ato de "fazer design".

O resultado físico dos produtos/objetos/artefatos caracteriza, em essência, a manifestação do pensamento do design, uma vez que integra uma variedade de problemas e restrições técnicas dentro de uma forma expressiva em particular que, por consequência, é responsável por proporcionar uma experiência estética mais holística ${ }^{16}$ : "a forma segue o significado".

Neste contexto, acreditamos que o design se traduz como agente promotor de valores imanentes mais significativos, capaz de contribuir para uma regeneração da cultura material, baseada na moderação do consumo e na aceitação da responsabilidade social que, naturalmente, e por sua vez, integra-se de maneira mais sustentável às esferas econômica e ambiental.

O esforço de Walker apoia-se em questões intrinsecamente extra materiais que não apresentam um caráter usual no âmbito mercadológico do design, tampouco logram - ao menos por enquanto - a devida credibilidade nas discussões regulares sobre sustentabilidade do meio acadêmico nacional. Ipso facto, podemos concluir que o epicentro da lógica referente à sustentabilidade, presente na obra de Walker, tanto na teoria, como na prática, através de seus objetos proposicionais, certamente pode ser considerada como uma abordagem radical.

\footnotetext{
15 "A Forma segue o Significado - Deste modo, o artesanato local é combinado com a produção em massa globalizada, materiais naturais e formas tradicionais com tecnologias digitais, e a funcionalidade de curta duração com o significado perdurável. A forma torna-se desvinculada da função. [...] Sua finalidade passa a estar tanto sobre a experiência estética e reflexão como sobre os requisitos de necessidade funcional. O resultado é um novo tipo de objeto híbrido que combina o velho e o novo, a razão e a intuição, o global e o local, onde a forma segue o significado" (Tradução nossa).

${ }^{16}$ PANTALEÃO; PINHEIRO. 2010.
} 


\section{REFERÊNCIAS}

CARDOSO, Rafael. Uma introdução à história do design. (3ạ ed.). São Paulo: Blucher, 2008.

PANTALEÃO, L. F.; PINHEIRO, O. J. Holoestética: Uma Abordagem Holística da Realidade em Arte e Design. In: 19 Encontro da Associação Nacional de Pesquisadores em Artes Plásticas, 2010, Cachoeira - BA. Anais do 19 Encontro Nacional da ANPAP (Online), 2010. p. 749-764.

PEARCE, David; MARKANDYA, Anil \& BARBIER, Edward B. Blueprint for a green economy. (4a ed.). Londres: Earthscan, 1989

RODRIGUES, Valdemar. J. Desenvolvimento sustentável: uma introdução crítica. Lisboa: Principia, 2009

WALKER, Stuart. Desmascarando o objeto: reestruturando o design para a sustentabilidade. In Revista design em Foco, v. II n.o 2, Jul/Dez 2005.

World, Abingdon: Routledge, 2014

Extant objects: designing things, as they are. Int. J. Sustainable

Design, Vol. 1, No. 1, 2008

Imagination's Promise: Practice-Based Design Research for Sustainability. In. WALKER, Stuart and GIARD, Jacques (orgs). The Handbook of Design for Sustainability, London: Bloomsbury Academic, 2013

. Sustainable by design: explorations in theory and practice. London:

Earthscan, 2006.

. The Spirit of Design: Objects, Environment and Meaning, Earthscan, London, 2011

Agradecemos à Fundação de Amparo à Pesquisa do Estado de São Paulo (FAPESP) sob processo n.o 2014/01356-6 que nos financia a pesquisa de onde resultou este artigo. As opiniões, hipóteses e conclusões ou recomendações expressas neste material são de responsabilidade dos autores e não necessariamente refletem a visão da FAPESP. 